\title{
Glenn T. Seaborg; discoveries; and the capital of knowledge
}

\author{
Balazs Hargittai · István Hargittai
}

Received: 30 March 2009/Accepted: 30 March 2009/Published online: 15 April 2009

(C) Springer Science+Business Media, LLC 2009

\begin{abstract}
Ten years from Glenn T. Seaborg's death we remember his achievements; his teaching about the importance of basic research is as timely as ever.
\end{abstract}

Keywords G. N. Lewis - Nuclear chemistry · Transuranium elements · Presidential advising · Twenty-first-century chemistry

“... knowledge capital-a product of basic research-... might also allow us to compensate somewhat for declining physical capital and higher cost resources."

Glenn T. Seaborg [1]

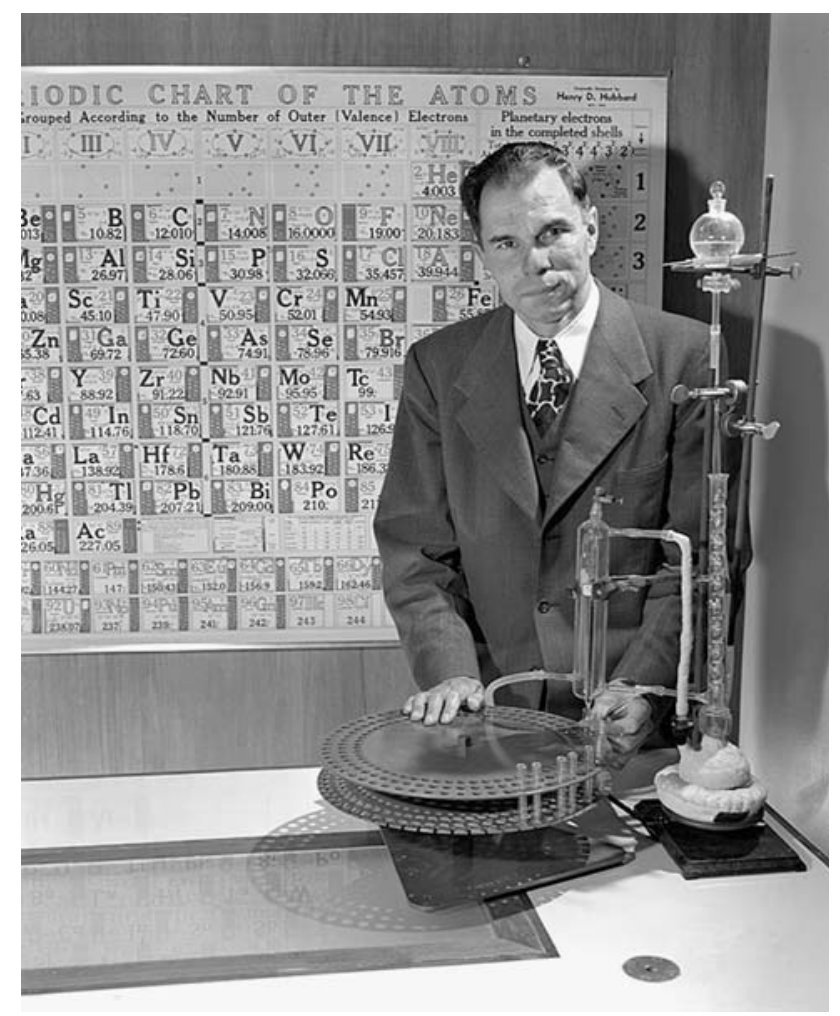

Glenn T. Seaborg (1912-1999) with ion-exchanger column of actinide elements in 1950 (courtesy of Lawrence Berkeley National Laboratory)

A giant of chemistry departed a decade ago the importance of whose oeuvre extends much beyond anniversaries; yet 10 years from his passing away provides a nice opportunity to make a special remembrance of him. He was born in a little mining town Ishpeming in Northern Michigan 1912, where his father was a machinist, which Seaborg thought was as close to science as somebody could

B. Hargittai $(\bowtie)$

Saint Francis University, 117 Evergreen Drive, Loretto, PA 15940, USA

e-mail: bhargittai@francis.edu

\section{Hargittai}

Department of Inorganic and Analytical Chemistry and Materials Structure and Modeling Research Group of the Hungarian Academy of Sciences, Budapest University of Technology and Economics, P.O. Box 91, H-1521 Budapest, Hungary e-mail: istvan.hargittai@gmail.com 
be in that environment. His entire family was Swedish and Swedish was the first language Seaborg learned to speak. In 1951, he started his Nobel address in his mother tongue. He shared the chemistry award with Edwin M. McMillan "for their discoveries in the chemistry of the transuranium elements. It was a long way from Ishpeming to Stockholm.

When Seaborg was 10 years old, the family moved to California, where he graduated from high school in Los Angeles in 1929. He became a student of the University of California at Los Angeles and received his bachelor's degree in Chemistry in 1934. For graduate studies, he moved to Berkeley and took his Ph.D. degree in Chemistry in 1937. He wrote his thesis about the inelastic scattering of neutrons. Following the receipt of his doctorate, Seaborg served as Gilbert N. Lewis's personal assistant at Berkeley for 2 years. Seaborg wrote warmly about this unique experience [2]. When he was asked to identify the greatest scientists he met during his long career, he named Lewis and Enrico Fermi.

Seaborg worked with an unusually large number of people on his many discoveries. He contributed to the discovery of 10 new elements and over a hundred new isotopes of elements. Much of his career was at the University of California at Berkeley where he became instructor of chemistry in 1939, assistant professor in 1941, and professor in 1945 .

Edwin McMillan led a group, which discovered element 93 by making uranium capture a neutron and, following beta-emission (the ejection of an electron from the nucleus) the element of atomic number 93 was formed. They called it neptunium, Np, after the planet Neptune orbiting next, outwards, after Uranus. After McMillan's departure for other defense-related research, Seaborg and his colleagues took over the project. They detected the next transuranium element, formed by another beta-emission; it had atomic number 94. It was given the name plutonium, $\mathrm{Pu}$, after Pluto, orbiting next outside Neptune, which at that time was considered to be a planet though today it no longer is. The nuclear reactions are depicted here in short-hand notation:

$$
\begin{aligned}
& { }^{92} \mathrm{U}-238+\mathrm{n} \rightarrow{ }^{92} \mathrm{U}-239 \\
& { }^{92} \mathrm{U}-239 \rightarrow{ }^{93} \mathrm{~Np}-239+\beta \\
& { }^{93} \mathrm{~Np}-239 \rightarrow{ }^{94} \mathrm{Pu}-239+\beta
\end{aligned}
$$

In 1941, Seaborg, together with Emilio Segrè and Joseph W. Kennedy, showed that plutonium was fissionable and it became the fuel of the second atomic bomb exploded over Nagasaki in 1945. In 1942, Seaborg joined the Manhattan Project and became a group leader at the Metallurgical Laboratory at the University of Chicago. Here it was that the non-fissionable uranium-238 isotope was converted into plutonium-239. The procedure was further developed at the Clinton Engineer Work in Oak Ridge, Tennessee, and served as the basis for the breeder reactors at the Hanford Engineer Works in Washington.

During World War II, there were frenetic activities in the research of the properties of newly discovered transuranium elements. Manuscripts describing the results were duly compiled and submitted to journals, but were voluntarily withheld from publication until the end of the war. Thus, for example the pivotal paper "Properties of 94(239)" was received by The Physical Review on May 29, 1941, but appeared only in the combined numbers 7 and 8, Volume 70, in October 1946.

After World War II, Seaborg returned to Berkeley, but remained also part of national politics through his much appreciated advising from President Truman to President Reagan. He was a member of the General Advisory Committee (GAC) at the time of the great debate about the issue whether the United States should embark on an accelerated program of developing the hydrogen bomb.

The GAC was an advisory body consisting of important scientists, which augmented the Atomic Energy Commission created after the war for directing American policy in matters of nuclear energy. The GAC held long sessions at the end of October 1949 and the outcome of the GAC meeting concerning the development of the hydrogen bomb could not have been easily predicted. On the one hand, there was the Soviet menace whereas on the other hand, the hydrogen bomb, utilizing thermonuclear reaction of fusion of light nuclei was promised to be a thousand times more powerful than the atomic bombs. Gradually, however, the scale during the sessions was increasingly shifting toward opposing a crash program to develop the thermonuclear bomb. The only dissenting voice was Glenn T. Seaborg's, who was the only member absent from the meeting, but who had sent a letter to the chairman of the GAC.

There were two crucial sentences in Seaborg's letter that showed unambiguously his stand in the matter of the discussion. Both sentences were formulated with utmost care and one can almost sense the tormenting hesitation of their author: "Although I deplore the prospects of our country putting a tremendous effort into this [the thermonuclear bomb], I must confess that I have been unable to come to the conclusion that we should not." Then, a little later in the letter, "My present feeling could perhaps be best summarized by saying that I would have to hear some good arguments before I could take on sufficient courage to recommend not going toward such a program."

Concerning his dissent from the rest of the GAC members in his letter to Oppenheimer, Seaborg could have raised his objections upon his return, during November and 
December, but he did not. At the time, Seaborg was a junior member of the GAC, who, eventually, would develop into a seasoned diplomat in addition to being a world-renowned scientist. Apparently he preferred to keep quiet for the duration of this debate. As is well known President Truman decided to have the hydrogen bomb developed. For a long time it was not known, but we know it today, that at the time of the American debate, the Soviet Union had already been deeply involved in developing its thermonuclear weapons.

Seaborg served as chairman of the U.S. Atomic Energy Commission for longer than anybody, between 1961 and 1971. During this decade he spent a lot of time in Washington, DC, whereas at other times he continued his research and educational activities at Berkeley. Considering Seaborg's principal role in the discovery of plutonium and in the determination of its properties, an embarrassing scene played out at a Senate hearing in 1970. It demonstrated the ignorance of the chairing senator when he asked Seaborg derisively, "What do you know about plutonium?" [3]. However, such episodes were rare and Seaborg enjoyed being involved in high politics for decades. Seaborg served 10 American presidents. He started keeping a journal at the age of 14, which was at the time of the Coolidge administration and published his documents and lessons from his encounters in 1998 [3].

Seaborg received many awards and distinctions, but none gave him as much joy as having an element named after him. In 1995, he was greatly disappointed when it seemed that this would not happen on account of his being alive and the appropriate organizations did not want to name an element after a living person. This followed a long story of sorting out the priorities in the discovery of element 106, because the discoverers have the right to propose a name for a new element.

The original discovery happened in 1974, and in 1993, the eight discoverers - members of the Lawrence Berkeley, including Seaborg, and the Lawrence Livermore Laboratories-were asked to suggest a name for the element. The votes diverged greatly; suggestions included Luis Alvarez, Frédéric Joliot, Isaac Newton, Thomas Edison, Leonardo da Vinci, Christopher Columbus, Ferdinand Magellan, Ulysses, George Washington, Peter Kapitza, Andrei Sakharov, and the country Finland. The group (without Seaborg) soon came together in a unified suggestion to name the element seaborgium after Seaborg. The final decision was made in Geneva on August 30, 1997 and seaborgium was adopted for element 106. Alas, Seaborg could not enjoy this new fame for long; 1 year later he suffered a stroke and died in half a year.
Of course, Seaborg's name is commemorated not only by element 106 , but also by his many other discoveries. He gave the periodic table of the elements its final form in that he designated the actinides their proper place. The actinides with atomic numbers $89,90,91$, etc., are characterized by their $5 f$ electron shell being gradually filled. The series starts with actinium just as the lanthanides start with lanthanum. The actinides have similar chemical properties; absorption spectra in aqueous solution and crystals; crystallographic characteristics; magnetic susceptibilities; and spectroscopic data [4]. When Seaborg came to his new theory of the actinide series, he shared it with some colleagues before he published it. People warned him that publishing his theory might ruin his reputation. This sort of caveat is common when discoverers come to revolutionary ideas. Seaborg, however, felt very sure of the correctness of his theory; besides, he did not think he had yet gained much reputation yet to ruin. He published his theory and gave a new appearance to the periodic table of the elements [5].

Seaborg's fascination with the new elements was shared by others. An article in the magazine Discover in 1998 compiled an address of an imaginary letter to Seaborg using only element names in the following way:

seaborgium (addressee: Seaborg)

lawrencium (Lawrence Laboratory)

berkelium (Berkeley)

californium (California)

americum (United States)

Seaborg himself gave the answer to the question of why it was so important for him to have an element named after him. He said that even one thousand years from now it will still be seaborgium whereas by then what he did would probably have long before disappeared in oblivion. He would have gladly traded away his Nobel Prize for having the element 106 named after him, had such an exchange been possible. In the end all turned out to be all right. Incidentally, when Seaborg noted that sooner or later his works will disappear from collective memory, he did his best to slow down such a process. He himself edited the publication of his selected papers and furnished the collection with his commentaries. Characteristically, the volume was titled Modern Alchemy referring to his feat of turning even ordinary elements into gold, alas, the economy of the process was not viable [6].

Part of Seaborg's legacy is his teaching and this is why, in conclusion, we quote Seaborg's thoughts for the future, which he sent one of us shortly before he passed away [1]: 


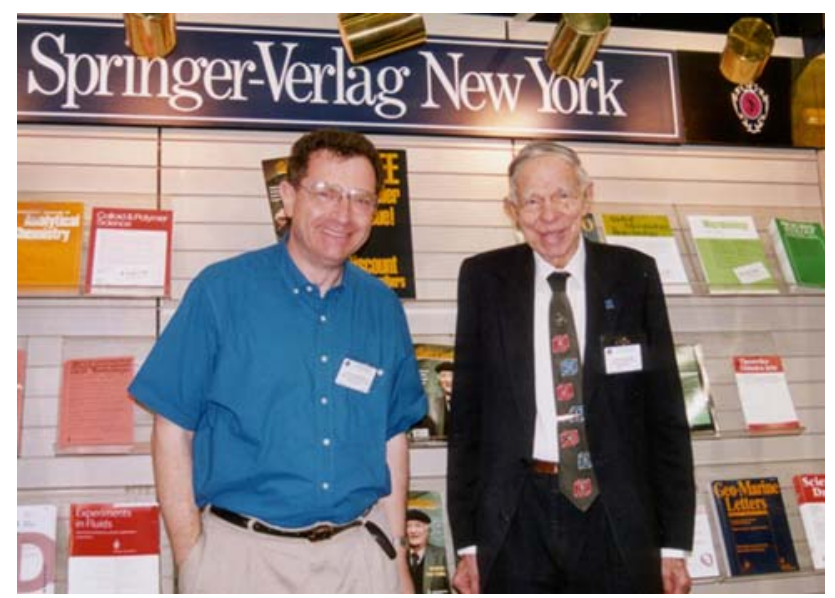

Glenn T. Seaborg and István Hargittai at the Springer-Verlag booth of the American Chemical Society spring 1995 meeting in Anaheim, California (by an unknown photographer)

Some Thoughts for the Future An important factor in the future, transcending the science of chemistry, will be the new public attitudes toward basic science and science in general - that is, the growing attitude toward ethical and human value considerations. The focus of this concern often is not on the question of whether the work is worth doing but instead on whether its potential harmful impact may outweigh any good it could do — that is, whether the research or project should be initiated at all. This attitude is affecting work on energy resources and technologies, biological research, aircraft development, and advances in the social sciences and education. This is going to have an increasing effect on the support and conduct of science, and I think most scientists are recognizing this.

As in the other cases of new influence, it is going to have its good and bad effects. Essentially, it is vital that science does serve the highest interest of society and contribute to the fulfillment of human values. And I believe that the science community for the most part is acting very responsibly and responsively in this direction. In many areas of research, such as genetic experimentation, atmospheric work, and the effects of chemicals on human health and the environment, it has taken the lead in placing human concerns above all.

But it should be realized that while there are certain values and ethical codes of a universal nature, there are also values that are more closely associated with the tastes, likes and dislikes, habits, and culturally induced beliefs of various individuals and groups attuned to certain so-called lifestyles. In a democratic society - and particularly one of growing advocacy and activism - there are bound to be many conflicts over these. And science and technology, with their increasing influence on life in general, certainly will be caught up in many of these. If this is the case, it may be essential that we find a way to establish some broad codes of conduct and values by which we can use science and technology to maximize human benefits within a framework of some type of consensus value scale. It seems to me that we must do this in order to avoid being paralyzed by a kind of case-by-case value judgment of all that we do. This does not mean that technology assessments and risk/ benefit studies of individual concepts should not be conducted. Nor does it mean that science should not maintain a most profound sense of responsibility toward safeguarding society from possible errors on its part or misapplications of its work. It does mean, however, that we must find a way to avoid having a "tyranny of parochial interests" when it comes to the possibility of advancing the general good through scientific progress.

Perhaps I can summarize by suggesting that future directions of chemistry, and science and technology in general, may be influenced by two broad goals: more fully establishing the boundaries-physical, environmental and social — in which we can operate; and providing the knowledge capital that will allow us to operate within them. That knowledge capital-a product of basic research-upon which we have drawn so heavily in the recent past and which we must replenish with new ideas might also allow us to compensate somewhat for declining physical capital and higher cost resources.

Finally, a few general thoughts. Our success in chemistry, and science in general, over the past century, and especially the last few decades, has brought us to a high level of material affluence, but this success also has fostered many new problems for the world. It also has given many people the notion that science should move us toward a utopian, problemless, riskless society. But this is a false notion. We live and always will live in a dynamic situation, amid problems whose solutions will breed other kinds of problems, and in a society where the leaps of progress will be proportionate to the risks taken. Even within the bounds of a "steady-state society," a "no-growth society," or any other scheme of populationresource-energy equilibrium we might achieve, there always will be change and creative growth that will challenge the human intellect. There always will be dangers, risks, and increasing responsibilities that will drive us toward a new level of excellence in all we do or try to achieve. This is the process of human 
evolution at work, a process that started with man's ascendancy and will continue for some time.

Acknowledgment Our research is being supported in part by the Hungarian Scientific Research Foundation (OTKA No. T046183).

\section{References}

1. Hargittai I (2003) Candid science III: more conversations with famous chemists "Glenn T. Seaborg". Imperial College Press, London, pp 2-17
2. Seaborg GT (1995) Chem Intelligencer 1(3):27-37

3. Seaborg GT (1998) A chemist in the White House from the Manhattan Project to the end of the Cold War. American Chemical Society, Washington, DC

4. Seaborg GT (1949) Nucleonics, November, 149-169

5. Clark DL, Hobart DE (2000) Los Alamos Science 26:56-61

6. Seaborg GT (ed) (1994) Modern alchemy: selected papers of Glenn T. Seaborg. World Scientific, Singapore 